\title{
BIOMASSA EM AULA PRÁTICA DE QUÍMICA ORGÂNICA VERDE: CRAVO-DA-ÍNDIA COMO FONTE SIMULTÂNEA DE ÓLEO ESSENCIAL E DE FURFURAL
}

\author{
Silvio Cunha*, Danilo Machado Lustosa e Nathan Dias Conceição \\ Instituto de Química, Universidade Federal da Bahia, Campus de Ondina, 40170-290 Salvador - BA / Instituto Nacional de Ciência \\ e Tecnologia - INCT em Energia e Ambiente, Universidade Federal da Bahia, Campus de Ondina, 40170-290 Salvador - BA, Brasil \\ Miguel Fascio e Vinícius Magalhães \\ União Metropolitana para o Desenvolvimento da Educação e Cultura, Av. Luis Tarquinio Pontes, 600, 42700-000 Lauro de Freitas \\ - BA, Brasil
}

Recebido em 6/6/11; aceito em 22/8/11; publicado na web em 26/9/11

\begin{abstract}
BIOMASS IN UNDERGRADUATE GREEN ORGANIC CHEMISTRY EXPERIMENT: ESSENTIAL OIL AND FURFURAL FROM CLOVE BUD. This work presents an optimized integrated experiment for isolation of clove bud essential oil, rich in eugenol, and subsequent utilization of the solid residue for furfural synthesis. The operationally simple laboratory protocols and utilization of water as a solvent in both operations, plus the use of biomass as the starting material for preparation of versatile intermediates in organic synthesis, make the experiments attractive for undergraduate experimental organic chemistry courses in the context of green chemistry. In addition, this is the first description of the use of biomass (clove bud) in the simultaneous preparation of two chemical feedstocks, eugenol and furfural, on experimental organic chemistry courses.
\end{abstract}

Keywords: green chemistry; undergraduate organic chemistry experiment; clove bud.

\section{INTRODUÇÃO}

"Pensar como Cientista e Atuar como Professor" é, para os da academia, o paradigma do nosso século que deve permear todas as ações do professor-pesquisador. Transpô-lo para atividades didáticas que impactem na formação das novas gerações de profissionais da Química, mais que desafiador, é necessário para formar os profissionais aptos à compreensão das demandas sociais relativas à energia, ao ambiente e à saúde, fomentando estes profissionais a atuarem no contexto da interdisciplinaridade, sustentabilidade e inovação. ${ }^{2-5} \mathrm{O}$ ensino em torno de um tema, mais que na disciplina, ainda que contido em um arcabouço disciplinar, é que melhor formará as novas gerações. ${ }^{2}$

Nesse contexto, o tema biomassa é um bom exemplo que pode ser explorado na formação experimental dos profissionais da Química. Existem vários relatos neste sentido, e não é novo o emprego de biomassa como matéria-prima para aulas de Química Orgânica. Todavia, a maioria das abordagens é estanque, sendo a biomassa empregada para produzir um único produto, quer seja um óleo essencial, quer seja um intermediário químico.${ }^{6,7}$ Experimentos desta natureza, demonstrando o aproveitamento de biomassa, cumpriram relativamente bem seu papel até o século passado, mas insistir em propostas centradas apenas na obtenção de um único produto a partir de uma dada biomassa é de pouco valor pedagógico, pois subestimam o potencial desta importante fonte renovável de insumos químicos valiosos e não proporcionam o aprendizado pleno dos princípios da Química Verde, essenciais à formação das novas gerações de profissionais. ${ }^{8-10}$

Em função dos cenários acima e do nosso envolvimento com o desenvolvimento de experimentos e estratégias para o ensino de Química Orgânica na graduação, ${ }^{11}$ descrevemos aqui uma contribuição que revisita o procedimento de obtenção do óleo essencial do cravoda-índia (Syzygium aromaticum), rico em eugenol - valioso tanto in natura quanto como fonte de intermediários químicos, Figura $1 .{ }^{12}$ As modificações consistem na otimização da etapa de hidrodestilação para que ocorra em tempo adequado a uma aula experimental de 2-3

*e-mail: silviodc@ufba.br h e ainda guarde relação adequada entre quantidade de óleo essencial obtido versus energia empregada e, mais importante, aproveitamos o resíduo sólido da hidrodestilação do cravo-da-índia para a preparação de mais um insumo químico, o furfural, que é um intermediário químico muito versátil em síntese orgânica, Figura $2 .{ }^{13}$

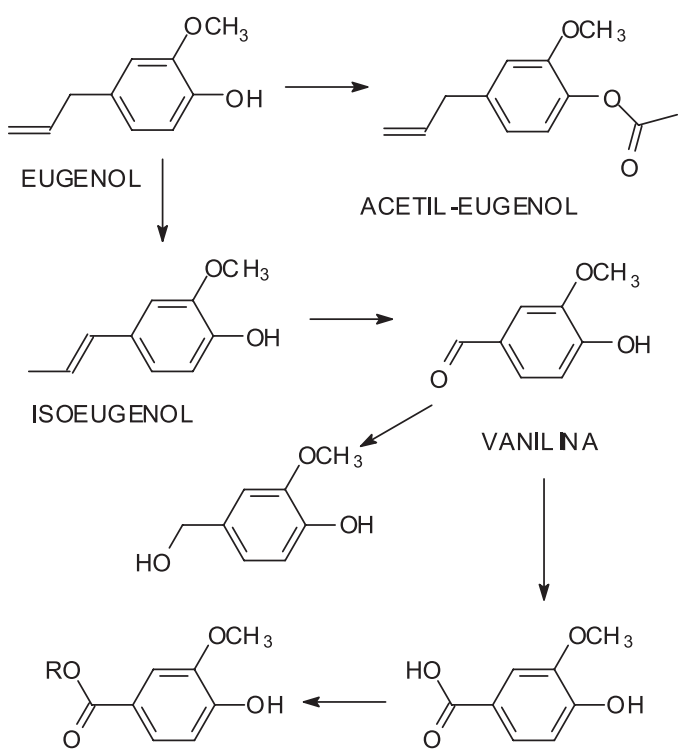

Figura 1. Intermediários preparados a partir do eugenol

\section{Revisitando o procedimento de obtenção do óleo essencial do cravo-da-índia}

A obtenção do óleo essencial do cravo-da-índia em aulas experimentais de química orgânica é bem conhecida, e alguns procedimentos clássicos estão disponíveis em livro texto e apostilas de cursos práticos disponíveis na internet. ${ }^{6,7}$ Estes procedimentos diferem na massa inicial de cravo e no tempo total do experimento. Todavia, as 


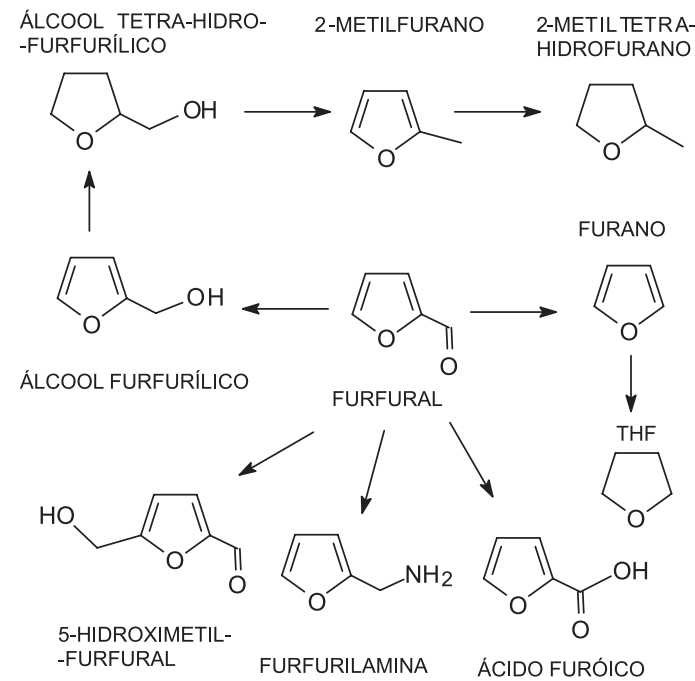

Figura 2. Intermediários preparados a partir do furfural

propostas de aproveitamento do cravo-da-índia envolvem apenas a obtenção do óleo essencial, sendo descartado o resíduo sólido final. Como a aula aqui proposta engloba a utilização do cravo-da-índia para a preparação do óleo essencial e, em seguida, do furfuraldeído, foi necessário reavaliar a massa inicial de biomassa a ser empregada e o tempo de experimento, adequando o tempo total dos dois experimentos, Figura 3. Na Tabela 1 encontra-se a variação da massa de óleo essencial obtida em função do volume de destilado extraído para diferentes amostras do cravo-da-índia adquiridas em mercado popular local. Assim, pode-se avaliar a influência da amostra na exequibilidade dos experimentos propostos.

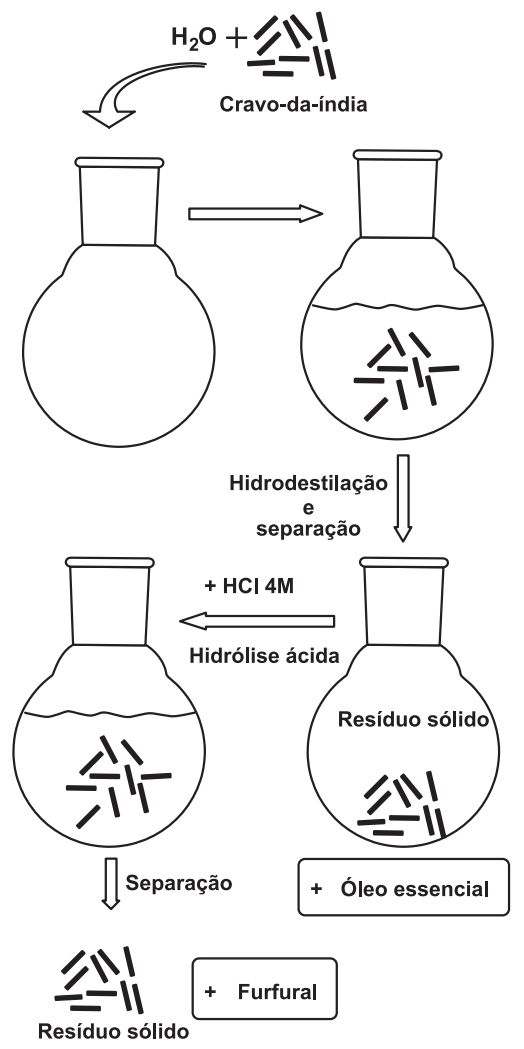

Figura 3. Representação esquemática da preparação dos intermediários químicos
Tabela 1. Massa de óleo essencial do cravo-da-índia em função da amostra $(10 \mathrm{~g})$ e volume de destilado coletado

\begin{tabular}{ccc}
\hline Destilação & Volume coletado $(\mathrm{mL})$ & Massa obtida $(\mathrm{g})$ \\
\hline 1 & 400 & 1,4774 \\
2 & 400 & 1,6120 \\
3 & 400 & 1,1458 \\
4 & 100 & 1,0500 \\
5 & 100 & 0,9303 \\
6 & 100 & 1,0221 \\
\hline
\end{tabular}

O emprego de massa superior a 10 g mostrou-se inviável para a realização dos experimentos sequenciais em apenas um período de aula. Dessa forma, fixando a massa do cravo-da-índia em $10 \mathrm{~g}$, pode-se tanto recolher $400 \mathrm{~mL}$ de destilado em aproximadamente $3 \mathrm{~h}$ de experimento, quanto cerca de $100 \mathrm{~mL}$ em $1 \mathrm{~h}$, sendo obtido sempre mais que $1 \mathrm{~g}$ do óleo essencial rico em eugenol, Tabela $1 .{ }^{14} \mathrm{~A}$ vantagem em recolher apenas os primeiros $100 \mathrm{~mL}$ consiste em empregar um volume de solvente orgânico extrator quatro vezes menor e a massa de óleo essencial obtida não é seriamente comprometida para os fins de uma aula experimental, como indicado na Tabela 1. Neste ponto, cabe ao instrutor adotar a melhor estratégia em função da natureza do curso, bem como incentivar a discussão sobre os princípios da química verde, como o cálculo do Fator E, para que os alunos discutam as implicações dos dois procedimentos. ${ }^{8,10}$

O óleo essencial foi analisado através das técnicas espectroscopia na região do infravermelho (IV) e cromatografia gasosa (CG). O espectro de IV obtido (Figura 1S, material suplementar) foi comparado com o espectro de amostra original do eugenol. Na cromatografia gasosa identificaram-se dois picos (Figura 2S, material suplementar), um mais intenso com tempo de retenção 5,4 min e outro com aproximadamente um décimo da intensidade do primeiro, com tempo de retenção de 7,5 $\min$ (este pico pode ser relacionado ao $\beta$-cariofileno ou ao acetato de eugenila, que são os dois outros componentes minoritários mais comuns, cerca de 7\%, do óleo essencial do cravo-daíndia). ${ }^{12}$ Comparando este cromatograma com os dados disponíveis na literatura, ${ }^{12}$ e em concordância com a análise do espectro de IV, atribuiu-se ao eugenol o pico de maior intensidade, comprovando que este é o componente majoritário, confirmado por coinjeção.

Com o procedimento otimizado aqui descrito é possível associar a obtenção do óleo essencial com a síntese do furfural, pois o estudante pode preparar a próxima etapa do aproveitamento do resíduo sólido do cravo-da-índia na mesma aula. Durante o período de maceração deste resíduo (ver abaixo) é feita a caracterização do óleo essencial, como descrito no parágrafo anterior.

\section{Preparação de furfural a partir do resíduo sólido da hidrodestilação do cravo-da-índia}

Nos procedimentos de obtenção do furfural destinados a aulas experimentais de química orgânica na graduação, a biomassa empregada é sempre o sabugo de milho. ${ }^{6}$ Dessa forma, reforça-se no estudante a noção limitada de aproveitamento da diversidade de biomassa, bem como sua utilidade na preparação de apenas um intermediário químico. Ao empregarmos o cravo-da-índia, adotamos a estratégia de aproveitar o resíduo sólido, que seria normalmente descartado, desenvolvendo um procedimento adequado para a síntese de furfural. Assim, utilizando a mesma biomassa de partida, dois intermediários passam a ser produzidos, Figura 3.

Foram desenvolvidos dois procedimentos para a síntese do furfural, que podem ser aplicados em aulas experimentais de curto ou longo pe- 
ríodos, de forma que a obtenção do óleo essencial e do furfural podem ser realizados na mesma aula ou em aulas consecutivas. Em ambos os procedimentos é necessário lavar o resíduo sólido da primeira etapa sucessivamente com água (ver Parte Experimental), caso contrário o furfural é obtido contaminado com o óleo essencial. Em seguida, o resíduo do cravo-da-índia é tratado com solução de ácido clorídrico 4 mol L-1 , podendo ser empregado dois tempos diferentes de maceração. No primeiro método deixa-se o resíduo macerar por 30 min na solução de $\mathrm{HCl}$ antes de iniciar a destilação para obter a solução aquosa do furfural. Este é o procedimento indicado para aulas experimentais de maior duração, onde a obtenção do óleo essencial e a preparação do furfural podem ser realizadas no mesmo dia. Para aula de menor duração a maceração ocorre por uma semana na solução de $\mathrm{HCl}$.

Para extrair o furfural do destilado, dois solventes foram avaliados para os dois tempos de maceração, Tabela 2. O emprego de éter etílico mostrou-se mais eficiente que diclorometano para o tempo de maceração maior, enquanto o uso de diclorometano proporcionou a obtenção de maior massa de furfural para o tempo de maceração menor. Todavia, cabe ao professor decidir qual solvente extrator empregar, levando em conta a disponibilidade do mesmo e a infraestrutura do laboratório, uma vez que ambos os solventes se mostraram adequados aos objetivos do experimento de aula de graduação e a variação da massa obtida é função da destreza do estudante e da natureza da amostra de biomassa empregada, pois amostras adquiridas de diferentes fornecedores renderam massas também diferentes.

Tabela 2. Massa de furfural em função de diferentes amostras de cravo (10 g), tempo de maceração e solvente de extração

\begin{tabular}{cccc}
\hline Amostra & $\begin{array}{c}\text { Tempo de } \\
\text { maceração }\end{array}$ & Solvente & $\begin{array}{c}\text { Massa obtida } \\
(\mathrm{mg})\end{array}$ \\
\hline 1 & $30 \mathrm{~min}$ & $\mathrm{Et}_{2} \mathrm{O}$ & 343,4 \\
2 & $30 \mathrm{~min}$ & $\mathrm{Et}_{2} \mathrm{O}$ & 100,0 \\
3 & $30 \mathrm{~min}$ & $\mathrm{CH}_{2} \mathrm{Cl}_{2}$ & 728,7 \\
4 & $30 \mathrm{~min}$ & $\mathrm{CH}_{2} \mathrm{Cl}_{2}$ & 547,1 \\
5 & 7 dias & $\mathrm{Et}_{2} \mathrm{O}$ & 356,0 \\
6 & 7 dias & $\mathrm{Et}_{2} \mathrm{O}$ & 100,2 \\
7 & 7 dias & $\mathrm{CH}_{2} \mathrm{Cl}_{2}$ & 189,6 \\
8 & 7 dias & $\mathrm{CH}_{2} \mathrm{Cl}_{2}$ & 81 \\
\hline
\end{tabular}

A presença do furfural no destilado foi comprovada através do teste com a 2,4-dinitrofenil-hidrazina, cujo produto foi isolado e caracterizado por comparação do espectro na região do infravermelho (Figura 4S, material suplementar) e determinação do ponto de fusão com os dados da 2,4-dinitrofenil-hidrazona preparada de amostra autêntica de furfural. Adicionalmente, a partir do furfural isolado, foram obtidos os espectros na região do infravermelho (Figura $3 \mathrm{~S}$, material suplementar) e de absorção molecular na região do UV-Vis (absorções máximas em 226 e 276, Figura 5S, material suplementar) e comparados com aqueles obtidos de uma amostra autêntica. É necessário destacar que esta é a primeira descrição de obtenção de furfural empregando cravo-da-índia.

Com a proposta de ampliar o escopo do experimento desenvolvido, o professor pode optar por quantificar o teor de furfural presente no destilado medindo a absorção de uma amostra na região do UV-Vis, empregando a equação da reta obtida da curva analítica construída com furfural padrão (Figura $6 \mathrm{~S}$, material suplementar).

\section{CONCLUSÃO}

Os experimentos aqui propostos abrangem diversas técnicas experimentais abordadas em disciplina experimental de química orgânica, tais como destilação, extração, filtração, cromatografia em camada delgada e determinação de ponto de fusão, contemplado ainda elucidação estrutural por teste químico de caracterização de grupo funcional, preparação de derivado e espectroscopia na região do infravermelho, bem como quantificação de analito orgânico por cromatografia gasosa e/ou absorção molecular.

A flexibilidade de execução permite adotar a preparação dos dois intermediários numa mesma aula ou em duas aulas consecutivas. Dessa forma, dependendo dos objetivos específicos da disciplina, o professor pode adaptar o experimento para atender a diversos aspectos pedagógicos, mesmo que disponha de aulas experimentais de 2-3 h de duração.

Tão importante quanto as características acima mencionadas, os experimentos associados de produção sequencial de mais que um insumo químico a partir da mesma biomassa com rendimentos satisfatórios (no experimento aqui desenvolvido, o furfural e o óleo essencial rico em eugenol, Figura 4), integrando os conhecimentos teóricos desenvolvidos na sala de aula, contribuem para inserir os princípios da química verde na formação experimental dos graduandos. Esta abordagem é, até onde sabemos, inédita em nossos cursos experimentais, o que reforça a necessidade de se desenvolver novos experimentos com este aspecto.

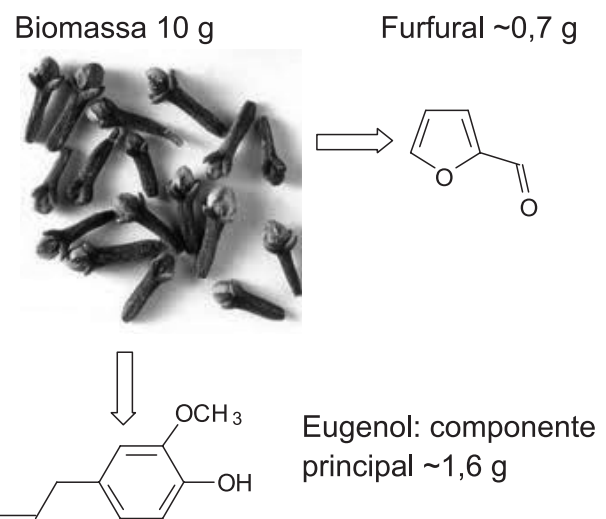

Figura 4. Óleo essencial e furfural obtidos da mesma amostra $(10 \mathrm{~g})$ do cravo-da-índia

\section{MATERIAL SUPLEMENTAR}

Cromatogramas e espectros nas regiões do infravermelho e do UV-Vis do óleo essencial e do furfural padrão, e curva analítica para o furfural encontram-se disponíveis gratuitamente em http://quimicanova.sbq.org.br, na forma de arquivo PDF.

\section{PARTE EXPERIMENTAL}

Os pontos de fusão foram determinados em um aparelho placa aquecida Microquímica MQAPF 301 e não foram corrigidos. Os espectros na região do infravermelho foram obtidos em disco de $\mathrm{KBr}$ ou filme, em um aparelho Shimadzu IR Affinity-1 ou FT-IR Bomem MB100. Os cromatogramas foram obtidos em aparelho GC-HP-5890, coluna DB-5, $30 \mathrm{~m}$ x 0,25 mm x 0,25 $\mu \mathrm{m}$, detetor de ionização de chama (temperatura $250^{\circ} \mathrm{C}, \mathrm{H}_{2} 30 \mathrm{~mL} / \mathrm{min}, \mathrm{N}_{2} 30 \mathrm{~mL} / \mathrm{min}$, ar sintético $300 \mathrm{~mL} / \mathrm{min})$. Condições da análise: temperatura do injetor $250{ }^{\circ} \mathrm{C}$, detetor $270{ }^{\circ} \mathrm{C}$, inicial da coluna $120^{\circ} \mathrm{C}$, final $250{ }^{\circ} \mathrm{C}$, gradiente 10 ${ }^{\circ} \mathrm{C} / \mathrm{min}-120^{\circ} \mathrm{C}, 2^{\prime} / 10^{\circ} \mathrm{C}^{\prime} / 250^{\circ} \mathrm{C}, 5^{\prime}$. Tempo total de análise de 20 min. Gás de arraste $\mathrm{H}_{2} 1 \mathrm{~mL}$ por min. Amostras injetadas com divisor 1:100. Os espectros de absorção molecular na região do ultravioleta foram determinados em solução aquosa, em aparelho Shimadzu UV Mini 1240. A 2,4-dinitrofenil-hidrazona do furfural foi preparada 
através do procedimento conhecido e suas propriedades comparadas com os dados da literatura. ${ }^{6,15}$

\section{Obtenção do óleo essencial do cravo-da-índia}

Em um balão monotubular de $250 \mathrm{~mL}$ adicionar $10 \mathrm{~g}$ de cravoda-índia e $100 \mathrm{~mL}$ de água destilada. Conectar ao balão um adaptador de Claisen e um condensador de tubo reto e aquecer a mistura até iniciar a destilação simples, recolhendo o líquido que destila a $99^{\circ} \mathrm{C}$. Para cada $50 \mathrm{~mL}$ de líquido recolhido na destilação adicionar, pelo adaptador de Claisen, $50 \mathrm{~mL}$ de água destilada ao balão contendo a mistura cravo/água. Alternativamente, a reposição de água ao balão de destilação pode ser feita à medida que ocorre a destilação, através de um funil de adição com água previamente conectado ao adaptador de Claisen ${ }^{7}$. Interromper o experimento quando forem recolhidos $400 \mathrm{~mL}$ do líquido destilado e extrair com éter etílico (3 x $90 \mathrm{~mL})$. Alternativamente, reservar os primeiros $100 \mathrm{~mL}$, deixando prosseguir a destilação até coletar mais $300 \mathrm{~mL}$ de líquido; os 100 primeiros $\mathrm{mL}$ recolhidos são extraídos com éter etílico $(3$ x $30 \mathrm{~mL})$. Reunir as fases orgânicas e secar o éter com sulfato de magnésio anidro, filtrar e eliminar o solvente em evaporador rotatório. Recolher e pesar a fração orgânica obtida. Alternativamente, pode-se pesar o balão que irá para a evaporação e, assim, determinar a massa obtida por diferença das massas do balão antes e depois da evaporação do éter. Caracterizar o óleo essencial.

\section{Obtenção do furfural empregando o resíduo do cravo-da-índia da hidrodestilação}

Após recolher $400 \mathrm{~mL}$ do hidrodestilado, lavar o resíduo do balão contendo o cravo-da-índia cinco vezes com $30 \mathrm{~mL}$ de água destilada e adicionar $50 \mathrm{~mL}$ de solução de $\mathrm{HCl} 4 \mathrm{~mol} \mathrm{~L}^{-1}$. Deixar a mistura fechada, em repouso, à temperatura ambiente por $30 \mathrm{~min}$ ou 7 dias (este tempo deve ser previamente definido pelo professor). Após este período, conectar ao balão um adaptador de Claisen e um condensador de tubo reto e aquecer a mistura até iniciar a destilação simples. Quando forem recolhidos 20 e $70 \mathrm{~mL}$ de líquido destilado, adicionar, pelo adaptador de Claisen, $50 \mathrm{~mL}$ de água destilada. Alternativamente, a reposição de água ao balão de destilação pode ser feita à medida que ocorre a destilação, através de um funil de adição com água previamente conectado ao adaptador de Claisen. Interromper a destilação quando $100 \mathrm{~mL}$ de líquido forem destilados. Submeter o líquido recolhido à extração com éter etílico ou diclorometano, empregando 3 extrações de $30 \mathrm{~mL}$ do solvente selecionado. Secar a fase orgânica com sulfato de magnésio anidro, filtrar e eliminar o solvente em evaporador rotatório. Recolher e pesar a fração orgânica obtida. Alternativamente, pode-se pesar o balão que irá para a evaporação e, assim, determinar a massa obtida por diferença das massas do balão antes e depois da evaporação do solvente. Caracterizar o furfural e preparar como derivado a 2,4-dinitrofenil-hidrazona e caracterizar (PF 226-228 ${ }^{\circ} \mathrm{C}$. Lit. ${ }^{15} 229^{\circ} \mathrm{C}$ ).

\section{AGRADECIMENTOS}

Ao suporte financeiro do Conselho Nacional de Desenvolvimento
Científico e Tecnológico - CNPq, da Coordenação de Aperfeiçoamento de Pessoal de Nível Superior - CAPES e da Fundação de Amparo à Pesquisa do Estado da Bahia - FAPESB. Agradecemos ao CNPq pelas bolsas de PIBIC de D. M. Lustosa e N. D. Conceição e à bolsa de produtividade em pesquisa de $\mathrm{S}$. Cunha.

\section{REFERÊNCIAS E NOTAS}

1. de Andrade, J. B.; J. Braz. Chem. Soc. 2009, 20, 575

2. Pinto, A. C.; Zucco, C.; de Andrade, J. B.; Vieira, P. C.; Quim. Nova 2009, 32, 567.

3. Galembeck, F.; Barbosa, C. A. S.; Sousa, R. A.; Quim. Nova 2009, 32, 571.

4. Ferreira, V. F.; Rocha, D. R.; Silva, F. C.; Quim. Nova 2009, 32, 623.

5. Mota, C. J. A.; Silva, C. X. A.; Gonçalves, V. L. C.; Quim. Nova 2009, $32,639$.

6. Soares, B. G.; Souza, N. A.; Pires, D. X.; Química Orgânica: Teoria e Técnicas de Preparação, Purificação e Identificação de Compostos Orgânicos, Ed. Guanabara S.A.: Rio de Janeiro, 1988; Pavia, D. L.; Lampman, G. M.; Kriz, G. S.; Engel, R. G.; Organic Laboratory Techniques Small-Scale Approach, Saunders College Publishing: New York, 1988

7. Berci Filho, P.; Porto, A. L. M.; Berlinck, R. G. S.; Laboratório de Química Orgânica II. Normas de Segurança e Práticas de Laboratório, disponível em graduacao.iqsc.usp.br/files/atualizaopraticaslabqumicaor ganicaII.pdf, acessada em Junho 2011.

8. Corrêa, A. G.; Zuin, V. G.; Química Verde: Fundamentos e Aplicações, EdUFSCar: São Carlos, 2009.

9. Centro de Gestão em Estudos Estratégicos, Brasília, 2010; Química Verde no Brasil 2010-2030, disponível em http://www.cgee.org.br, acessada em Junho 2011.

10. Lenardão, E. J.; Freitag, R. A.; Dabdoub. M. J.; Batista, A. C. F.; Silveira, C. C.; Quim. Nova 2003, 26, 123; Dupont, J.; Quim. Nova 2000, 23, 825; Prado, A. G. S.; Quim. Nova 2003, 26, 738; Merat, L. M. O. C.; Gil, R. A. S.; Quim. Nova 2003, 26, 779.

11. Cunha, S.; Quim Nova 2008, 31, 906; Cunha, S.; Beretta, M.; Fascio, M.; Santos, A. O.; Rodrigues Jr., M. T.; Bastos, R. M.; Quim. Nova 2005, 28, 364; Cunha, S.; Lião, L. M.; Bonfim, R. R.; Bastos, R. M.; Monteiro A. P. M.; Alencar, K. S.; Quim. Nova 2003, 26, 425; Cunha, S.; Quim Nova 2003, 26, 948; Lopes, W. A.; Fascio M.; Quim. Nova 2004, 27, 670 .

12. Arenas, D. R. M.; Ruíz, F. A. R.; Kouznetsov, V. V.; Tetrahedron Lett. 2011, 52, 1388; Bizzo, H. R.; Hovell, A. M. C.; Rezende, C. M.; Quim. Nova 2009, 32, 588; Craveiro, A. A.; de Queroz, D. C.; Quim. Nova 1993, 16, 224.

13. Corma, A.; Iborra, S.; Velt, A.; Chem. Rev. 2007, 107, 2411.

14. Se o professor optar por recolher os $100 \mathrm{~mL}$ iniciais da etapa da hidrodestilação é necessário deixar a destilação continuar até recolher mais $300 \mathrm{~mL}$, para que o resíduo do cravo-da-índia possa ser empregado na próxima etapa de síntese do furfural. Este procedimento proporciona a obtenção do furfural não contaminado com eugenol.

15. Shriner, R. L.; Fuson, R. C.; Curtin, D. Y.; Morrill, T. C.; Identificação Sistemática dos Compostos Orgânicos, $6^{\mathrm{a}}$ ed., Editora Guanabara Dois S.A.: Rio de Janeiro, 1983. 


\section{BIOMASSA EM AULA PRÁTICA DE QUÍMICA ORGÂNICA VERDE: CRAVO-DA-ÍNDIA COMO FONTE SIMULTÂNEA DE ÓLEO ESSENCIAL E DE FURFURAL}

Silvio Cunha*, Danilo Machado Lustosa e Nathan Dias Conceição

Instituto de Química, Universidade Federal da Bahia, Campus de Ondina, 40170-290 Salvador - BA / Instituto Nacional de Ciência e Tecnologia - INCT em Energia e Ambiente, Universidade Federal da Bahia, Campus de Ondina, 40170-290 Salvador - BA, Brasil Miguel Fascio e Vinícius Magalhães

União Metropolitana para o Desenvolvimento da Educação e Cultura, Av. Luis Tarquinio Pontes, 600, 42700-000 Lauro de Freitas - BA, Brasil

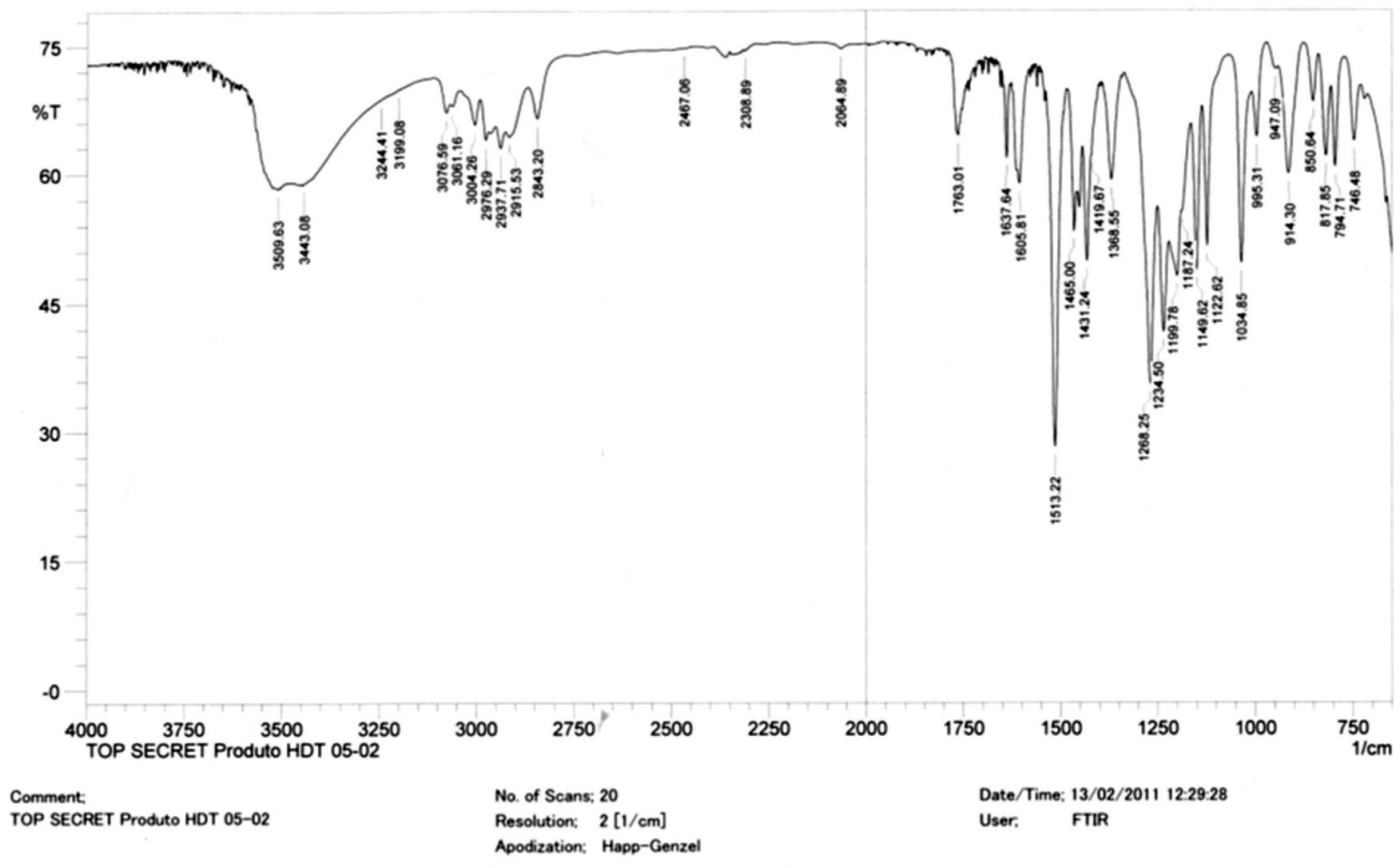

Figura 1S. Espectro na região do infravermelho do óleo essencial do cravo-da-índia 


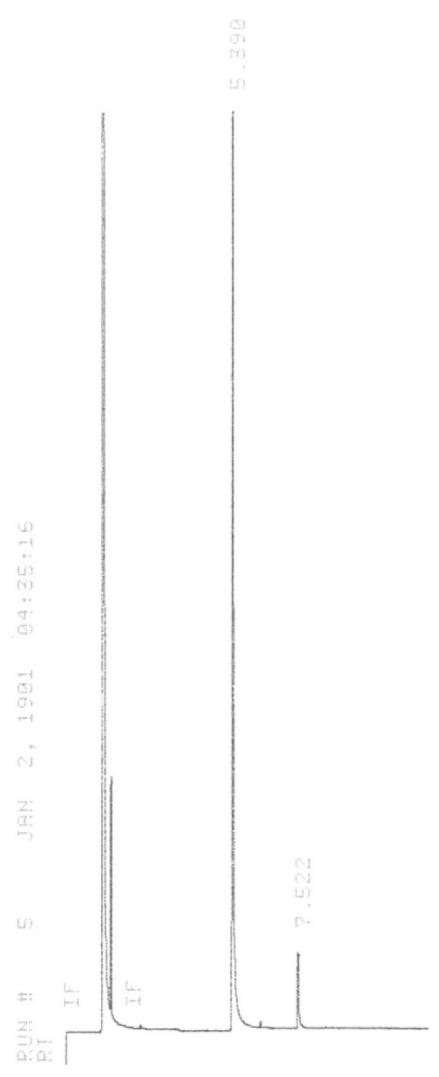

Figura 2S. Cromatogramas do óleo essencial da hidrodestilação do cravo-da-índia (esquerda) e do furfural (direita)

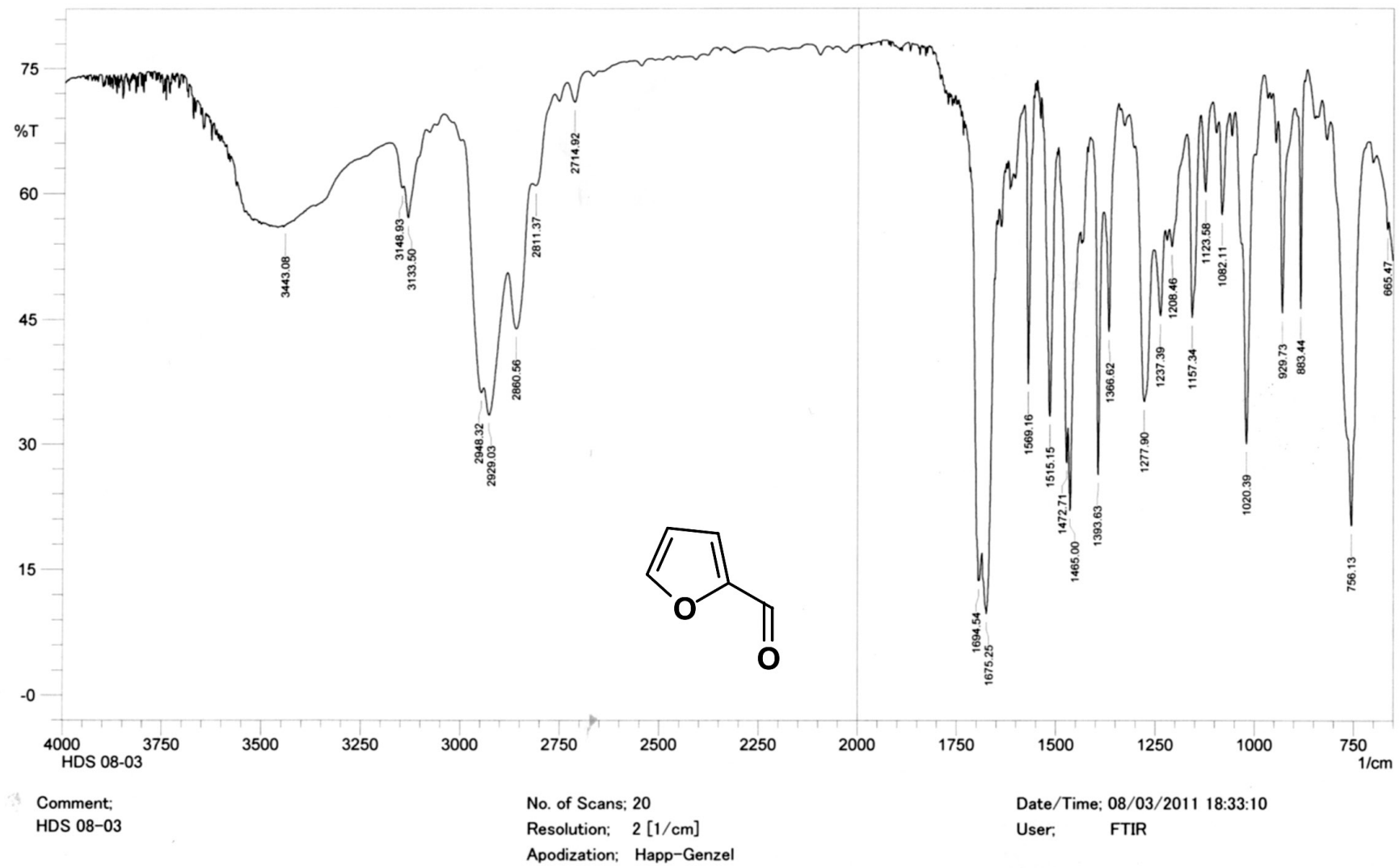

Figura 3S. Espectro na região do infravermelho do furfural obtido do cravo-da-índia 


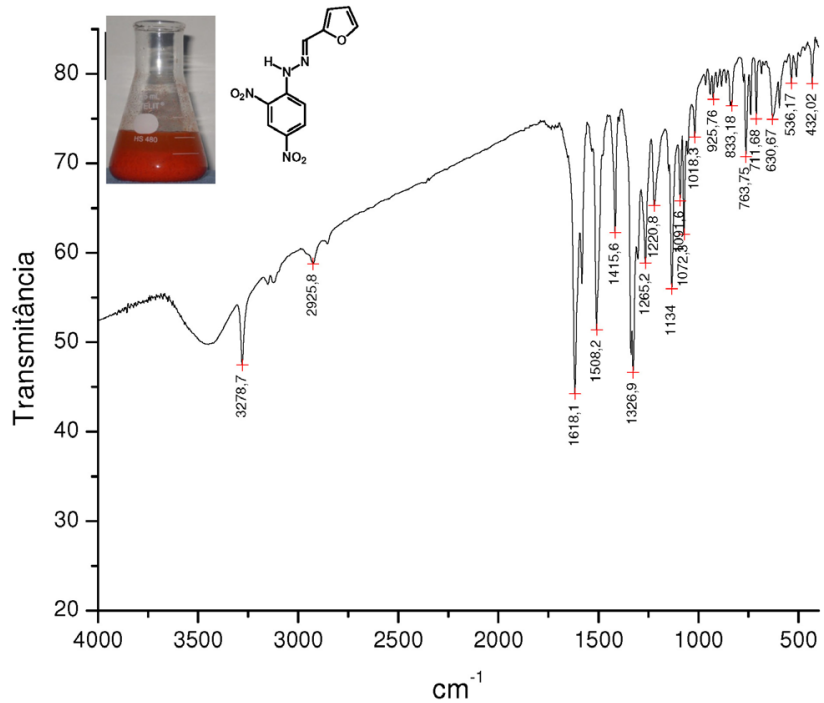

Figura 4S. Espectro na região do infravermelho da 2,4-dinitrofenil-hidrazona do furfural obtido do cravo-da-índia e representação da sua precipitação
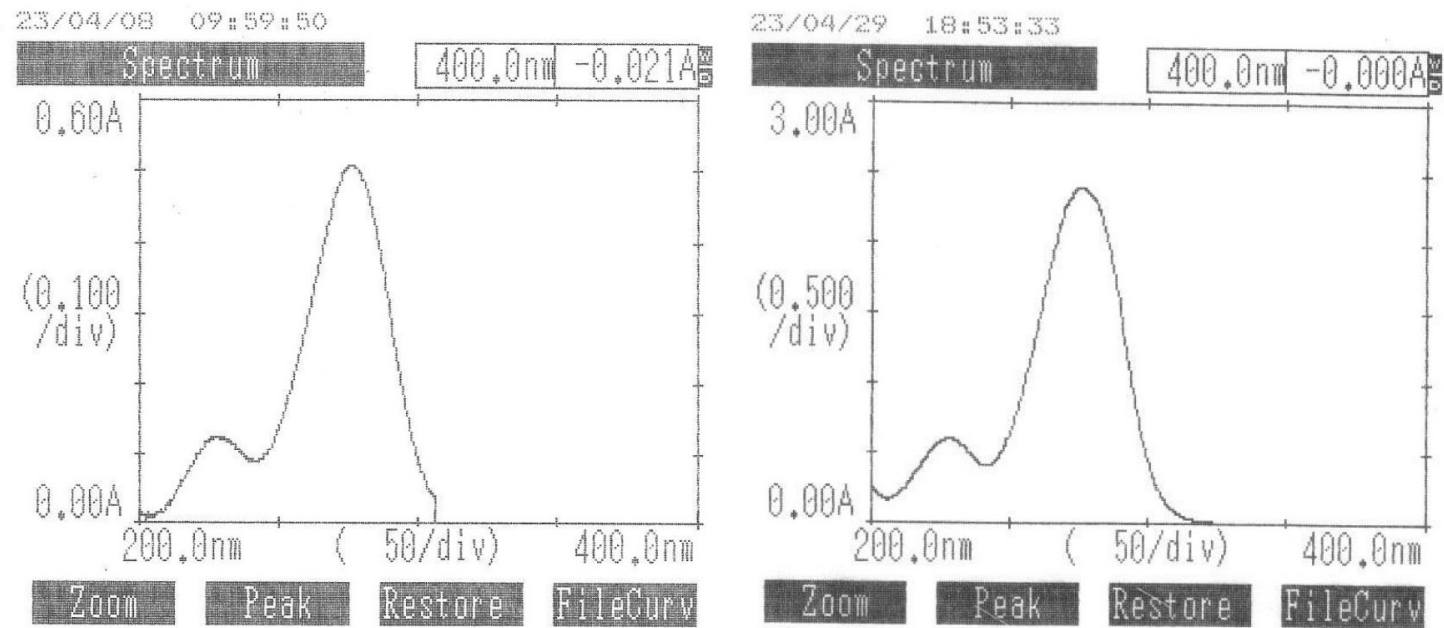

Figura 5S. Espectros de absorção molecular do furfural padrão (esquerda) e do obtido do cravo-da-índia (direita) com máximos em 226 e 276 nm

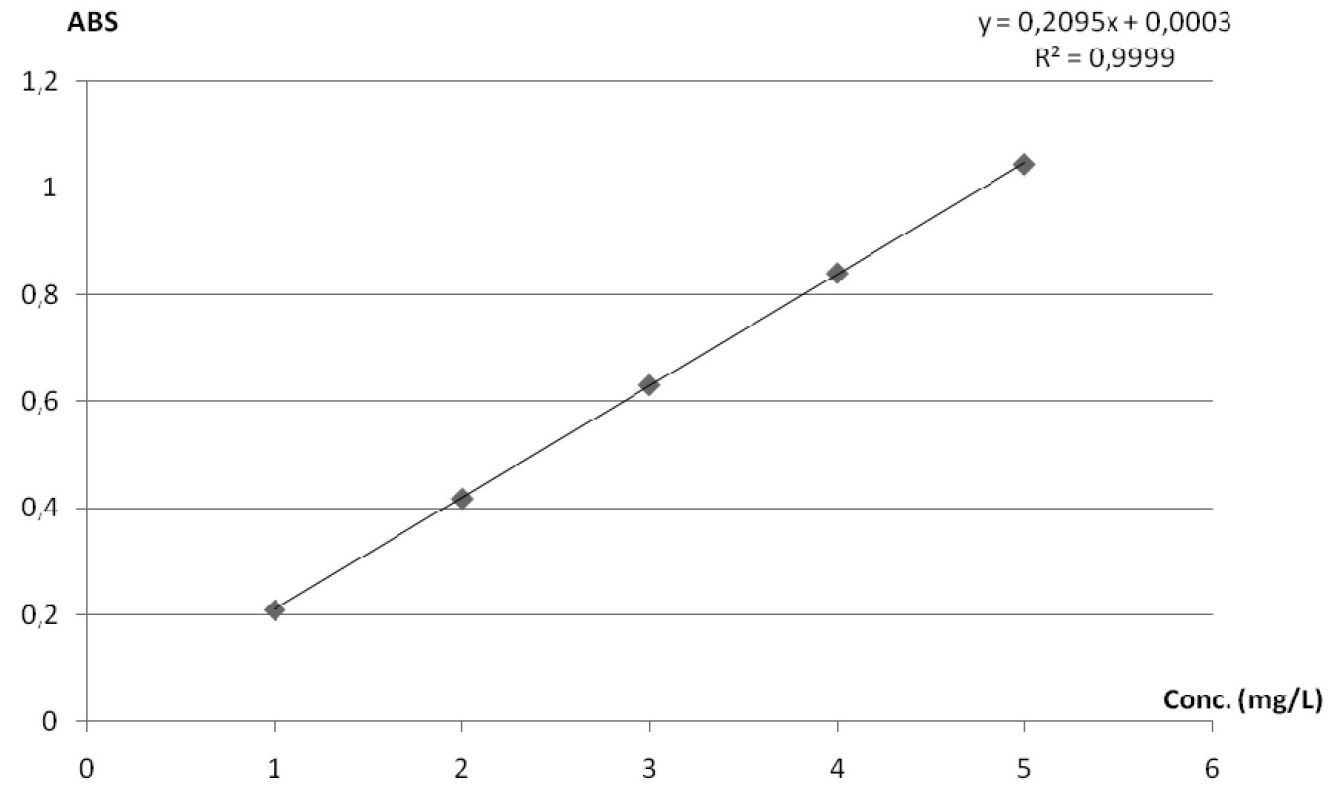

Figura 6S. Curva analítica para o furfural na região do ultravioleta $(276 \mathrm{~nm})$ 